\title{
The Interaction Between Depression and Personality Dysfunction: State of the Art, Current Challenges, and Future Directions. Introduction to the Special Section
}

\section{La Interacción entre Depresión y Disfunción de la Personalidad: Estado del Arte, Desafios Actuales y Direcciones Futuras. Introducción a la Sección Especial}

\author{
Alex Behn \\ Pontificia Universidad Católica de Chile \\ Sabine C. Herpertz \\ Ruprecht Karls Universität Heidelberg \\ Mariane Krause \\ Pontificia Universidad Católica de Chile

\begin{abstract}
This paper introduces the Special Section on Depression and Personality, first, by presenting an outline of relevant research on the interaction between depression and personality dysfunction and, then, by mapping the contributions of the authors on current challenges and future directions in the field. The intersection between affective disorders and personality dysfunction is relevant in at least 2 general ways. First, it signals a new direction in clinical research that calls for an emphasis on underlying functional domains and personality characteristics, rather than on phenotypic presentations of depression. Second, it challenges the effectiveness of usual treatment protocols for patients with complex depression. Both directions in research are naturally linked: new treatments should be based on interventions that map on deficits in functional domains as well as on personality characteristics that influence clinical presentation and responses to treatment. The Special Section will introduce the reader to scientific work carried out by the Millennium Institute for Research in Depression and Personality, which tackles some of these important issues.
\end{abstract}

Keywords: depression, personality dysfuntion, borderline personality disorder

Se introduce la Sección Especial sobre Depresión y Personalidad, presentando un resumen de la investigación relevante sobre la interacción entre la depresión y la disfunción de la personalidad y haciendo un mapa de las contribuciones de los autores sobre los desafíos actuales y las direcciones futuras en este campo. La intersección entre trastornos afectivos y disfunción de la personalidad es relevante en al menos 2 formas: (a) señala una nueva dirección en la investigación clínica, exigiendo un énfasis en los dominios funcionales subyacentes y las características de la personalidad, en lugar de las presentaciones fenotípicas de la depresión y (b) discute la efectividad de los protocolos de tratamiento habituales para la depresión compleja. Ambas direcciones en la investigación están naturalmente vinculadas: los nuevos tratamientos deben basarse en intervenciones que mapeen los déficits en los dominios funcionales y en las características de la personalidad que influyen en la presentación clínica y las respuestas al tratamiento. La Sección Especial introduce al lector al trabajo científico realizado por el Instituto Milenio para la Investigación en Depresión y Personalidad, que aborda algunos de estos importantes temas.

Palabras clave: depresión, disfunción de la personalidad, trastorno límite de la personalidad

The collection of scientific articles presented in this Special Section on Depression and Personality of Psykhe constitutes a significant milestone within the systematic scientific agenda developed at the Millennium Institute for Research in Depression and Personality (MIDAP). MIDAP's explicit scientific aim is to provide high-quality evidence regarding the complex and multi-dimensional relations between depression and personality. The fact that a sizable collection of empirical papers can be produced, reviewed,

Alex Behn and Mariane Krause, Escuela de Psicología, Pontificia Universidad Católica de Chile, and Millennium Institute for Research in Depression and Personality, Santiago, Chile; Sabine C. Herpertz, Heidelberg University Hospital, Ruprecht Karls Universität Heidelberg, Germany.

The production of this article was supported by CONICYT/PCI, Project PII20150035, and by the Fund for Innovation and Competitiveness (FIC) of the Chilean Ministry of Economy, Development and Tourism, through the Millennium Science Initiative, Grant N IS130005.

Correspondence concerning this article should be addressed to Mariane Krause, Escuela de Psicología, Pontificia Universidad Católica de Chile, Avda. Vicuña Mackenna 4860, Macul, Santiago, Chile. E-mail: mkrause@uc.cl 
BEHN, HERPERTZ AND KRAUSE

and published when MIDAP is about to complete its fourth year of existence is remarkable. It signals scientific productivity and density. At the same time, it presents the scientific community with well-known challenges in the pursuit of systematic research in depression and personality. Conceptual, diagnostic, methodological, and clinical problems about depression and personality are numerous. No consensus exists in the field as to common instrumentation to be used in studies addressing depression and personality and a plurality of heuristic concepts appear to be relevant to capture aspects of the relationship between depression and personality. Study designs vary, with more and more data stemming from prospective longitudinal designs, particularly from ambitious cohort studies that have produced an increasingly robust corpus of scientific evidence concerning, for example, the significant contribution of early adverse experiences in the development of complex forms of depression that are typically related to personality dysfunction, treatment resistance, and more chronic courses. Genetic and epigenetic studies have shared additional light into the complex interactions between genetic vulnerabilities and environmental factors that contribute to severity of depressive disorders and of personality pathology. Psychosocial variables, such as income disparity, have also been shown to impact mental health markers, including treatment response in depressed patients and access to appropriate services. MIDAP's scientific work aims to understand depression and personality from the perspective of a multidimensional model that takes into account culture, social context, development of cognitions-emotions-behavior, psychophysiology, and genetics.

In regard to all these components of a complex and ambitious multidimensional model, where depression is nested within personality, the contribution of one single research institute is likely to be limited. On this point, the collection of articles presented in this Special Section is at the same time an achievement and a marker of how much research is still needed in the future. MIDAP is entering a critical phase, one in which its research agenda will be consolidated toward focused scientific goals to be obtained in the next five years. The articles presented here are likely to contain - at different stages of development-the seeds of the future work of the Institute, work that will surely lead to a substantial contribution to the field. In this respect, the Special Section cannot be more timely.

To introduce the Special Section, we will present a review of contemporary problems regarding the interaction between depression and personality dysfunction. In doing so, we do not present a comprehensive review of general aspects of a broader relationship between mood and personality. Such reviews exist (see Klein, Kotov, \& Bufferd, 2011). Rather, we present contemporary problems that are pertinent to the research aims of MIDAP and that provide a scientific frame for the specific collection of articles presented in this Special Section. We start with a discussion about current diagnostic controversies and provide evidence for two competing models of the relationship between depression and personality dysfunction, namely a common causes model and a predisposition model. Of note in this review is our focus on borderline personality disorder (BPD). We justify this decision because: (a) it is a well-known fact that the majority of the research in pathological personality dysfunction is centered around systematic empirical research in BPD (Leichsenring, Leibing, Kruse, New, \& Leweke, 2011) and (b) it is likely that BPD constitute a prototypic presentation with sufficient symptomatic coverage of other forms of personality dysfunction (see Wright \& Zimmermann, 2015, for a review). We then move towards an evidence-based clinical discussion on the subject of psychotherapy research in depression and personality dysfunction. Finally, in view of this discussion, we present the collection of papers included in the Special Section and discuss future directions in the field, specifically, in the production of MIDAP's scientific outcomes.

\section{Diagnostic Controversies and the Frequent Co-occurrence of Depression and Personality Pathology}

The interaction between depression and personality dysfunction has been a matter of scientific and clinical debate ever since systematic empirical research on personality pathology emerged in the 1980s, about three decades later than systematic empirical research on depression. Landmarks studies that have characterized the occasional polarization of this debate include, from the mood disorders specialist perspective, Akiskal and McKinney Jr.'s (1973) widely cited study published in Science, arguing that depression is a single and stable clinical entity with rather strong diagnostic borders with other clinical entities. On the personality disorders specialist side, Gunderson and Phillips (1991) have argued that the most prototypical personality disorder, namely BPD (regarding the status of BPD as a prototypical personality disorder presentation, Wright \& Zimmermann, 2015, offers a comprehensive review), exhibits weak and non-specific relationships to depression. Ten years later, Akiskal et al. (1985) directly negated the 
diagnosis of BPD, indicating that it could be efficiently included within the diagnostic margins of depressive disorders (e.g., within the depressive spectrum; Angst \& Merikangas, 1997). However, significant research has showed that first line psychotherapeutic and pharmacological interventions to alleviate depressive mood have a diminished effect in patients with BPD and that depressive symptoms can remit with successful treatment of BPD (Gunderson et al., 2004), indicating that mood instability in the setting of personality pathology may exhibit a different pathogenesis (Stoffers et al., 2010). This debate is still quite active and, according to recent accounts, "(...) the problem of the boundaries of mood and personality disorder is central to the identity of psychiatry and to its future" (Paris, 2015, p. 7).

\section{Evidence for Depression and BPD as Distinct, yet Commonly Co-occurring Entities}

The relationship between depression and personality dysfunction has been often framed in terms of a common-cause model (Klein, et al., 2011). This model predicts that depression and personality are distinct entities, but share common etiopathogenetic mechanisms. However, there are no causal influences between both entities in this specific model. In other words, patients frequently present with depression and personality dysfunction, because both problems have the same or similar causal influences, but a patient's depression is not caused by his or her personality problems. A recent review by Goodman, Chowdhury, New, and Siever (2015) has argued that major depressive disorder (MDD) and BPD are likely two distinct disorders, sharing common disease mechanisms that account for affective dysregulation, regardless of specific phenotypes. Depressive disorders and personality disorders, in particular BPD,-which likely constitutes a prototypical presentation in the realm of personality dysfunction-mainly overlap in the functional domain of affect regulation, that is, they share affective symptomatology. Clinically, BPD patients very often present with a major depressive episode (Newton-Howes et al., 2014). This co-occurrence has also been explained in terms of a diathesis of affective regulation, by an etiological influence related to the personality trait of negative affectivity or neuroticism (Reichborn-Kjennerud et al., 2010; Wright et al., 2012). Negative affectivity expresses a heritable trait characterized by exacerbated negative emotions, sensitivity, and reactivity to stress (Widiger, 2009). In a meta-analysis, the negative affective trait managed to explain almost $30 \%$ of the variability in BPD symptoms and $22 \%$ of the variability in symptoms of an major depressive episode, suggesting an underlying etiological dimension to both disorders (Kotov, Gamez, Schmidt, \& Watson, 2010; Samuel \& Widiger, 2008).

Initial accounts indicated that while in depression mood disturbances were episodic, more sustained, and less reactive to environmental stressors, mood dysregulation in BPD exhibited more intense fluctuations and high reactivity to environmental and, in particular, interpersonal stressors (Gunderson, 2007) and specifically sensitivity to interpersonal rejection (Staebler, Helbing, Rosenbach, \& Renneberg, 2011). However, data from longitudinal studies has revealed that the difference between episodic and stable mood symptoms in MDD and intense fluctuations in BPD is not necessarily warranted. Depression often exhibits a recurrent course with inter-episodic maintenance of residual symptoms (Frodl, Möller, \& Meisenzahl, 2008) or even a chronic course from the beginning (Klein, 2010). Notably, early-onset forms of chronic depression typically go along with severe impairment of interpersonal functioning, similar to those found in personality disorders (Klein 2010), and have been conceptualized as a personality disorder in previous times (Herpertz, Steinmeyer, \& Saß, 1998). BPD patients, on the other hand, typically stop presenting diagnostic threshold symptomatology as time passes (Paris \& Zweig-Frank, 2001; Zanarini, Frankenburg, Hennen, Reich, \& Silk, 2005). A recent study using frequent ecological momentary assessment showed that MDD with BPD patients did not present with higher affective instability, compared to MDD patients (Köhling, Ehrenthal, Levy, Schauenburg, \& Dinger, 2015). The fact that MDD and BPD phenotypes of affect dysregulation are not easily distinguished provides compelling evidence for shared disease mechanisms.

Taking this evidence into account, strong phenotypic differences between MDD and BPD are not quite as clear as initially had been thought. In fact, phenotypic stability of disorders is largely discussed in current research, particularly in light of recent large scale studies that have argued for the presence of one common factor underlying pathways to severity across formerly called Axis I mental disorders (Caspi et al., 2014), as well as across personality disorders (Sharp et al., 2015). Regarding the later, the most recent version of the International Classification of Diseases (ICD-11) eliminates the specific classes of personality disorders (e.g., narcissistic, histrionic, and schizoid) and presents dimensional criteria for one single personality disorder, based on domains of functioning and a five-factor model of personality traits, while retaining BPD as qualifier of severity (Herpertz et al., 2017). This diagnostic modification in the realm of personality disorders was already available in part in the hybrid alternative model presented in DSM-5 (Widiger, 2011), which also 
BEHN, HERPERTZ AND KRAUSE

relies on domains of functioning (which result in dimensional assessment of personality pathology) and on personality traits (which can lead to a categorical diagnosis based on specific trait configurations). Both modifications are substantial and contribute to solve the problem of frequent comorbidity among different personality disorders (Clark, 2005), underlining the idea of a single personality dysfunction component which can present phenotypic variability as a function of profiles of maladaptive personality traits.

\section{Evidence for a Specific Phenotype of Depression in Personality Pathology}

The idea of two distinct yet commonly co-occurring disorders is largely sustained by the evidence pointing towards common disease mechanisms (i.e., a shared diathesis in affect regulation). From this perspective, of course MDD and BPD will often present together. However, authors have also advanced the idea of specific forms of depression that are secondary to personality dysfunction. This causal influence of personality over depression can be understood from the perspective of a predisposition model (Klein et al., 2011), which predicts that specific depressive phenotypes stem from specific personality vulnerabilities.

Most prominently, Sydney Blatt proposed in 1974 that depression may be a by-product of deficits in the structure of object relations, further advancing the idea of two distinct forms of depression, namely, anaclitic and introjective (Blatt, 1974). In his effort to understand the heterogeneity of depressive presentations, Blatt argued that anaclitic depression was characterized by a disruption of interpersonal relatedness (typically fears of abandonment), whereas introjective depression was characterized by deficits in self-integrity and in self-esteem (typically extreme self-criticism; Blatt \& Zuroff, 1992). This initial distinction was further developed into a comprehensive theoretical model connecting personality predispositions with stressful life events. The latter is quite interesting, given the pertinence of the early life maltreatment literature to understand depression, personality pathology, and the interaction between the two (Heim \& Binder, 2012; Pagano et al., 2004). Recently, Silva et al. (2017) have provided experimental evidence indicating that biological stress reactivity of individuals is modulated by their positioning within an anaclitic or introjective polarity of experience, with introjective individuals exhibiting more objective biological stress reactivity compared to anaclitic individuals, but anaclitic showing higher scores in self-report instruments. Thus, personality predispositions in the anaclitic versus introjective continuum provide a specific vulnerability for the development of depression, particularly when an individual is confronted with stressors.

Within the predisposition model, depression in the setting of BPD has been often investigated as a specific depressive phenotype alongside the literature on phenotypic heterogeneity of depression. This phenotype of borderline depression would be characterized mainly by accelerated patterns of emotional variability (Mneimne, Fleeson, Arnold, \& Furr, 2018; Trull et al., 2008), emerging and hardly identifiable with retrospective self-reports, since these frequently over-represent extreme or concurrent affective states at the time of answering the questionnaire, not knowing the moment-to-moment variability in mood (Fredrickson, 2000; Hufford, Shiffman, Paty, \& Stone, 2001). In addition, patients with borderline depression would exhibit greater impulsivity, aggressiveness/hostility and interpersonal hypersensitivity (Fertuck, Grinband, \& Stanley, 2013; Rogers, Widiger, \& Krupp, 1995). They are also patients who would present a greater risk of developing self-injurious and/or suicidal behaviors (Lieb, Zanarini, Schmahl, Linehan, \& Bohus, 2004). In summary, this particular phenotype would be characterized, therefore, by emergent and rapid psychic variability and by characteristic components of $\mathrm{BPD}$, including affective dysregulation, impulsivity and behavioral dysregulation, and interpersonal hyper-responsiveness (Gunderson \& Lyons-Ruth, 2008). This evidence may contribute to differential diagnosis between concurrent MDD and BPD, on the one hand, and borderline depression, on the other.

The predisposition model predicts that depression is tributary to, not concurrent with, the personality dysfunction. A careful evaluation of the level of the personality dysfunction within a continuum of severity is called for and prescribed by current diagnostic guidelines, including the ICD-11 and the DSM-5 alternative model. The level of personality function can be most aptly evaluated within the spectrum of self-other representations (Leising \& Zimmermann, 2011). In this respect, the Operationalized Psychodynamic Diagnosis (OPD) system has offered a useful theoretical and empirical framework for research and for clinical use (OPD Task Force, 2008). The OPD is a psychodynamically-informed multiaxial system, initially developed over 25 years ago with the goal of providing a reliable diagnostic and research tool that would allow a more comprehensive evaluation of patient's functioning, beyond symptomatic presentations typically covered by standard diagnostic manuals. A comprehensive review of the OPD system can be found elsewhere (for example, in Cierpka, Grande, Rudolf, von der Tann, \& Stasch, 2007). We will focus our discussion on axis 
IV, which covers the concept of structure and that is useful to evaluate levels of personality functioning. Specifically, OPD operationalizes structure in terms of self-other functioning, including perception and cognition of the self and others, regulation of self and others, regulation of internal versus external representations of others, and the level of attachment to internal and external representations of the self and others (Zimmermann et al., 2012). What is essential to our current discussion is that the level of personality functioning assessed through the OPD system appears to be sensitive in distinguishing between borderline depression and MDD comorbid with BPD, because it exhibits high correlations with clinically rated personality disorders, but not with axis I diagnoses. This may indicate that the OPD system may go beyond the fact that MDD and BPD have likely common causes and provide subtle coverage of the predispositional component in borderline depression (Zimmermann et al., 2012).

\section{Psychotherapy Research at the Intersection Between Depression and Pathological Personality Dysfunction}

The overlap and differentiation of depressive disorders and personality pathology, in particular BPD, is not only a matter of academic concern; it has direct consequences over clinical case management, including diagnosis and differential treatment indication and planning. Additionally, the relationship between depression and personality dysfunction can be further examined when treatment response and treatment change mechanisms are studied in addition to diagnostic markers. Consider a patient diagnosed concurrently with depression and BPD. Both pathologies, as predicted by the common cause model, likely share a problem in the functional domain of affect regulation. However, following this model, both entities, depression and BPD, are also independent. Nevertheless, if we consider treatment responses as an additional component, as established by Newton Howes's meta-analysis (Newton-Howes et al., 2014), specifically patients with MD and personality pathology have a high risk of becoming non-responders in a variety of treatments, including psychotherapy. If both problems are independent, why is the response in comorbid patients lower? Treatment research provides important evidence, in this case suggesting a negative influence of pathological personality dysfunction on depression's susceptibility to be improved with standard treatment. Surprisingly, very few studies have tackled this question explicitly, perhaps because for decades the poorer outcome of comorbid depression and personality pathology patients has been part of the "clinical wisdom" and, as such, it functions ideologically-being considered an obvious thing that does not require further research. A widespread idea in standard psychiatric practice that likely stems from a categorical view of mental disorders is that, even though comorbidity is common, both classes of disorders develop in parallel avenues and personality pathology does not necessarily have an impact on Axis I diagnosis and prognosis (Tyrer et al., 2007). Thus, for comorbid patients that are referred primarily for depressive symptoms, the clinical center of attention may not habitually be placed on personality pathology. An insufficiently integrative treatment focus added to a strict adherence to treatment manuals that is standard procedure for clinical trials may be partially responsible for the poorer outcomes of patients with comorbid depression and personality pathology. There is, however, as argued by Crawford et al. (2008), sufficient evidence that personality pathology has a specific effect on treatment outcome above and beyond typical treatment deficiencies of research-designed interventions. For example, using data from the collaborative longitudinal personality disorders study, Shea et al. (2004) observed that higher chances of remission from depression were related to higher chances of remission from BPD at a two-year follow-up. In a six-year follow-up study of patients with axis I and BPD comorbidity, Zanarini, Frankenburg, Hennen, Reich, and Silk (2004) found that patients with depression comorbid with BPD had fewer chances of remission from their personality pathology than those patients who did not meet criteria for a mood disorder at intake, evidencing a reciprocal (and vicious) influence of both disorders. Based on these findings that stem from the treatment literature, it is likely that change trajectories in both dimensions (depression and personality) are related and do not follow independent, parallel tracks.

Contemporary psychotherapy research on change mechanisms in the treatment of depression and personality dysfunction has concentrated mainly on emotional processing and regulation, as well as on sociocognitive processing (Kramer, 2017). This is in line with a common cause model positing that affect regulation is a shared causal influence for depression and BPD, on the one hand, and a predisposition model indicating that problems such as interpersonal hypersensitivity are at the root of borderline depression, on the other (Köhling et al., 2015). As argued by Kramer (2017) in a recent review, these components of change need to be studied from a variety of methodological perspectives, including, of course, quantitative as well as qualitative strategies. Additionally, different samples should be used to assess change at different developmental levels. Finally, different sets of outcome measures should be used in the study of change during psychotherapy for 
BEHN, HERPERTZ AND KRAUSE

patients with depression and personality dysfunction, including regular, self-report measures, as well as neurobiological markers, which have been already extensively used in BPD treatment research to cover affect dysregulation (Schnell \& Herpertz, 2018) and interpersonal hypersensitivity markers (Herpertz \& Bertsch, 2015).

While specific evidence-based treatment approaches do exist to address depression (Barth et al., 2016) and personality pathology (i.e., BPD; Leichsenring et al., 2011) independently, the prospect of working effectively with patients with complex or borderline depression may require an additional set of tools to be added to standard treatment manuals or guides (Schnell \& Herpertz, 2018). These treatment augmentations appear to be best delivered as modules, and effective modules should be primarily designed to address affective and socio-cognitive processing deficits, because these problems have been consistently associated with psychopathological markers of complex depression and with change processes in mediation psychotherapy studies for these patients, as well as in in-depth qualitative studies of patients extracted from mediation studies (Levy et al., 2017). Following Blatt's polarities of depressive experience, change mechanisms in psychotherapy also map on decrements in self-criticism and/or dependency and specific modules can be designed to help with self-esteem and particular with pathological self-criticism (Luyten, Lowyck, \& Batt, 2017).

Clinically, the perspective that common deficits in the functional domain of affect regulation may be shared by depression and personality pathology has contributed to the development of modular, patienttailored interventions that may be suitable treatment approaches for cases in the intersection between depression and personality pathology (Schnell \& Herpertz, 2018). Additional interventions that target deficits in functional domains, either shared between depression and personality pathology or specific to each disorder, have also been developed. For example, affect dysregulation can be effectively targeted with interventions from dialectical behavioral therapy (DBT; Neacsui, Eberle, Kramer, Weismann, \& Linehan, 2014). Additional strategies to improve affect regulation have been summarized by Gross (2014). In the realm of social cognition and interpersonal hypersensitivity - frequently impaired in patients with BPD with and without MDD - the functional domain of reflective functioning can be targeted using active components from mentalization based therapy (Bateman \& Fonagy, 2012). DBT also provides a set of skills to improve interpersonal effectiveness (Byrne \& Egan, 2018), as well as an adapted version of interpersonal psychotherapy (Markowitz, Skodol, \& Bleiberg, 2006).

\section{The Articles Contained in the Special Issue}

In order to address or further develop the etiopathogenic, diagnostic, methodological, and clinical issues that we discussed above, extensive scientific work needs to be carried out. The collection of articles presented in this Special Section provide a sample of the work being carried out at MIDAP. Six empirical articles are presented, each examining a different aspect of the relationship between depression and personality dysfunction. First, de la Parra et al. ("Personality Structure in Patients with Depression: Adaptation of an Instrument and Preliminary Results") address the problem of adequate instrumentation by presenting results of an adaptation for a university in Santiago, Chile, of the OPD-SQ questionnaire to assess personality functioning from the perspective of the OPD (Dinger et al., 2014; Zimmermann et al., 2012). The development or local adaptation of reliable instrumentation is important for clinical as well as for scientific aims. Thus, the article presented by de la Parra et al. provides local researchers with a powerful diagnostic and research tool in the form of a self-report questionnaire that, at least preliminarily, appears to have robust psychometric properties. The OPD-SQ is particularly well suited for research in patients with depression and personality dysfunction, because it covers, among other components, affect regulation, interpersonal functioning, and self-criticism, which, as we discussed above, are prominent hallmarks of the intersection between depression and pathological personality dysfunction.

Using the OPD-SQ, the article by Dagnino et al. ("The Impact of Personality and Depressive Style on the Psychotherapeutic Outcomes of Depressed Patients") provides integrative evidence of the intersection between personality organization, depressive experience (Blatt's polarity), and changes in well-being during naturalistic psychotherapy at two psychotherapeutic care centers in Santiago, Chile. As can be expected, correlations between structural integrity and pathological domains of depressive experience (high selfcriticism or high dependency) were found at the beginning of the treatment. Beyond this initial finding, Dagnino et al. further examine facets of personality integration in their relationship to depressive experience and change in well-being up to the sixth session of naturalistic psychotherapy, showing that patients high in 
dependency exhibit more marked positive change during treatment. This relevant finding contributes to the idea that different profiles of depression in connection to personality dysfunction may lead to differential treatment response and, thus, may call for adaptive treatment targeting, for example, using specific treatment modules. According to Dagnino et al., self-critical patients may require an additional set of interventions to help with treatment gains.

Mellado et al. ("Self-Criticism in in Patients with Depression and its Impact on Dropout in Short-Term Psychotherapies: Exploring the Mediator Role of the Therapeutic Alliance and the Moderator Role of Patients' Age") study the extent to which self-criticism and dependency impact retention rates during brief psychotherapy at a private health center in Santiago, Chile. Whereas patients high in dependency stay in therapy longer, self-critical patients struggle to stay in the treatment. These findings have many clinical implications, primarily related to initial strategies deployed by therapists to retain patients presenting introjective (high self-critical) depression. An interesting discussion regarding the interaction between patient age and self-criticism is presented by Mellado et al., where the relationship between dropout and selfcriticism appears to mainly impact patients that are older than 40 years. This type of finding may be easily integrated into the research about modular interventions that target deficits in domains of functioning. From this perspective, a specific module designed for patient retention may be developed and tested for patients high on self-criticism, particularly for those within the age range where a stronger association between selfcriticism and dropout is found.

The article by Valdés, Gómez, and Reinel ("Moments of Rupture and Resolution of the Therapeutic Alliance in the Case of an Adolescent Diagnosed with Identity Diffusion: Their Impact on Psychotherapeutic Outcomes") presents a single case study that lies at the heart of the process research tradition that has been part of MIDAP's scientific agenda, with a recent fund awarded by the Chilean Government to MIDAP for the development of a Latin-American Psychotherapy Process Research Network. Valdés et al. provide much needed evidence about the process of change in adolescent patients suffering from identity diffusion. In line with recommendation for research in change mechanisms for patients with pathological personality dysfunction (Kramer, 2017), Valdés et al. use a mixed design to examine the relationship between moments of rupture in the alliance, resolution strategies implemented by the therapist, and treatment outcome. This case is of particular interest for the examination of the complex relationship between depression and personality. The patient, a female adolescent presented primarily with depression, also exhibited consistent markers of identity diffusion. In order to treat the patient's depression, the treatment targeted underlying deficits in identity integration as they manifested themselves in the therapeutic relationship. From the perspective of differential treatment algorithms for patients with depression in the setting of personality dysfunction, this case presentation provides compelling evidence for the relevance of an alliance module containing tools that may help clinicians repair ruptures in the alliance.

What changes in psychotherapy? This question is, as we discussed above, typically addressed in mediation research, using longitudinal measurements in variables of interest. This has led to the demonstration by Kramer (2017) that in successful treatment of patients with personality disorders change may be expected in patients that improve coping behaviors, which, in turn, may positively influence affect regulation and socio-cognitive processing. However, and also in the setting of adolescent patients presenting depression, Cortés, Fernández, Capella, Espinosa, and Krause ("What Changes in Psychotherapy? The Perspective of Adolescents with Depressive Symptoms, Their Therapists, and External Observers") pursue this question from a different, quite informative-however often neglected-perspective, namely, the perspective of patients, their therapists and external observers. In this qualitative study, Cortés et al. conduct post-therapy follow-up interviews of six adolescents and their therapists in four health centers in Santiago, Chile. They further compare interview data with expert ratings, using the generic change indicators coding system developed by Krause, Altimir, Pérez, and de la Parra (2015), all researchers at MIDAP. Convergences and divergences between perspectives are productively discussed by the authors in light of the importance of integrating different outcome perspectives to understand therapeutic change. Even though Cortés et al. do not explicitly discuss personality dysfunction, the idea of including additional perspectives regarding what constitutes change in therapy may be extremely relevant for research in depression in the setting of personality dysfunction. In their qualitative study, Cortés et al. show that adolescent patients and external observers place more emphasis in intra-psychic changes, whereas therapist appear to be more concerned with behavioral, extra-session changes. Most research in BPD treatment addresses objective changes in impulsivity (e.g., suicidality) and affective dysregulation symptoms (e.g., BDI scores). However, it is not clear 
if these change parameters are equality relevant for patients, and in this sense, the model proposed by Cortés et al. indicates a promising direction in research.

Finally, León, Olhaberry, Hernández, and Sieverson ("Couple Satisfaction and Depression: Is the Reflective Functioning an Intervening Variable?") extend the scope of research in depression and personality dysfunction, beyond psychotherapy research, into the study of dyadic precursors of depression. In this study (50 couples with children under three years old of the Metropolitan Region of Chile), reflective functioning (a common functional domain, well studied in the treatment of patients with BPD) was predicted to play a moderating role between couple satisfaction and depressive symptomatology in members of the couple. Even though correlational evidence between couple's satisfaction and depression is well documented and replicated (Fincham, Beach, Harold, \& Osborne, 1997), the combined focus with reflective functioning as a moderator is new. Leon et al. show that in couples with higher reflective functioning, the relationship between couple's satisfaction and depression becomes stronger. This finding is quite interesting, indicating that higher levels of reflective functioning may lead to increased levels of depression in couples. It is possible that an improved capacity for self and other observation may lead to a more accurate estimation of the couple's real difficulties, and this may partially explain higher levels of depression. The article of León et al. is also quite interesting, because it moves the discussion about the relationship between domains of personality functioning (i.e., reflective functioning) and depression beyond individual psychopathology.

\section{Discussion}

The field of research in depression and personality dysfunction is undergoing important transformations. Conceptualizations of personality pathology are shifting from categorical to dimensional frameworks. Specific types of personality pathology are being removed from classifications and are replaced by profiles of personality traits. Beyond phenotypes, functional domains underlying symptomatic presentations are being examined and posit interesting avenues towards etiopathogenetic models and treatment development, particularly modular interventions. Personality functioning lies at the heart of a person's psychological makeup, and thus, it is bound to be related with common pathological presentations, including depression. Of particular interest for the scientific development of MIDAP is the intersection between personality dysfunction and depression. In this introduction to the Special Section on depression and personality, we have outlined competing models regarding the relationship between both problems, with a focus on MDD and BPD. We have discussed a common-cause model which predicts that comorbidity between depression and BPD is explained by the fact that both share etiopathogenetic mechanisms, particularly problems in the functional domain of affect regulation. We have also discussed the predisposition model, which predicts that patients suffering from BPD will often present with depression, because the personality dysfunctions in functional domains underlying BPD elevates the risk for depressive symptoms (e.g., interpersonal rejection sensitivity outpatients at risk for depressive reactions to real or perceived abandonment). Both, commoncauses and predispositions may explain both heterogeneity in depressive presentations and differential response to standard treatment packages. Distinguishing between depressive phenotypes stemming from common causes or from predispositions poses interesting scientific, methodological, and clinical challenges.

These problems are at the center of MIDAP's scientific activity and the collection of papers presented in the Special Section provides specific advancements of the clinical and scientific problems we presented above. First, instrumentation issues are addressed and the local research community is presented with an adapted version of the OPD-SQ, which provides specific coverage of difficulties in structural integrity. The development and adaptation of reliable instrumentation to evaluate deficits in domains of personality functioning is essential to the clinical and empirical project of relating specific profiles of depression to specific deficits in functional domains. Differential treatment allocation will evidently rely heavily on the use of accurate and reliable assessment of personality functioning. The development and testing of appropriate instrumentation remains a challenge in the field and certainly in the context of MIDAP's scientific work. The proliferation of idiosyncratic scales and interview schedules needs to be kept at a minimum within the field, and certainly within the scientific activity of MIDAP.

Secondly, the Special Section presents the reader with compelling evidence regarding different types of depressive presentations as related to either anaclitic or introjective depressive experiences. Introjective, and in particular self-critical patients, benefit less from psychotherapy and exhibit more treatment dropout. Anaclitic, and specially dependent patients typically exhibit more adherence to treatment. The clinical importance of this differential initial diagnosis of two distinct depressive profiles is clear and prescribes 
interventions to target self-criticism and also, perhaps, to address motivation and improve treatment retention. Differential diagnosis of depressive profiles as related to problems in domains of personality functioning and adaptive treatment indication based on depressive profiles and underlying personality dysfunction will continue to grow in importance and concentrate significant portion of MIDAP's scientific research agenda. This will certainly allow for the possibility of more personalized treatments and even "precision psychotherapy".

Thirdly, the Special Section presents the reader with the idea that research in depression and personality dysfunction requires a combination of methodologies, with mixed, quantitative and qualitative designs, probably yielding superior data in relation to the development of comprehensive models. The need of broadening the sources of outcome data to include both different reporters and different variables, including well-being in addition to symptomatic burden, is also signaled by the articles contained in the Special Section. It also presents the reader with the importance of studying the relationship between depression and personality dysfunction in different patient populations, including adolescents and parental dyads.

Finally, the importance of working with alliance ruptures and reparations in patients with depression and personality dysfunction is presented specifically for the treatment of an adolescent patient with identity diffusion, but certainly it signals the general relevance of the model spearheaded by Safran, Muran, Samstag, and Stevens (2001) related to clinical work with the alliance. This technical component of psychotherapy appears to be of particular importance in the treatment of depressed patients with BPD, because interpersonal hypersensitivity is likely driving much of the affective variability. Contrary to psychotherapy with depressed patients without BPD, the development of a stable alliance of good quality is an achievement of the treatment, not a pre-requisite.

The Special Section presented in the current number of Psykhe is an invitation to learn about the scientific work carried out at MIDAP. At the same time, it presents a window to some of the most difficult to solve issues in clinical psychology and psychiatry, issues that are at the center of current discussion in the field, one that is undergoing major transformations. In any case, this Special Section is bound to spark the interest of the clinical as well as the scientific reader.

\section{References}

Akiskal, H. S., Chen, S. E., Davis, G. C., Puzantian, V. R., Kashgarian, M., \& Bolinger, J. M. (1985). Borderline: An adjective in search of a noun. The Journal of Clinical Psychiatry, 46, 41-48. Retrieved from https://www.ncbi.nlm.nih.gov/pubmed/3968045

Akiskal, H. S. \& McKinney Jr., W. T. (1973). Depressive disorders: Toward a unified hypothesis. Science, 182, 20-29. https://doi.org/10.1126/science.182.4107.20

Angst, J. \& Merikangas, K. (1997). The depressive spectrum: Diagnostic classification and course. Journal of Affective Disorders, 45, 31-40. https://doi.org/10.1016/S0165-0327(97)00057-8

Barth, J., Munder, T., Gerger, H., Nüesch, E., Trelle, S., Znoj, H. ... Cuijpers, P. (2016). Comparative efficacy of seven psychotherapeutic interventions for patients with depression: A network meta-analysis. Focus, 14, 229-243. https://doi.org/10.1176/appi.focus.140201

Bateman, A. W. \& Fonagy, P. (Eds.) (2012). Handbook of mentalizing in mental health practice. Arlington, VA: American Psychiatric Publishing.

Blatt, S. J. (1974). Levels of object representation in anaclitic and introjective depression. The Psychoanalytic Study of the Child, 29, 107-157. https://doi.org/10.1080/00797308.1974.11822616

Blatt, S. J. \& Zuroff, D. C. (1992). Interpersonal relatedness and self-definition: Two prototypes for depression. Clinical Psychology Review, 12, 527-562. https://doi.org/10.1016/0272-7358(92)90070-O

Byrne, G. \& Egan, J. (2018). A review of the effectiveness and mechanisms of change for three psychological interventions for borderline personality disorder. Clinical Social Work Journal, 46, 174-186. https://doi.org/10.1007/s10615-018-0652-y

Caspi, A., Houts, R. M., Belsky, D. W., Goldman-Mellor, S. J., Harrington, H., Israel, S. ... Moffitt, T. E. (2014). The p factor: One general psychopathology factor in the structure of psychiatric disorders? Clinical Psychological Science, 2, 119-137. https://doi.org/10.1177/2167702613497473

Cierpka, M., Grande, T., Rudolf, G., von der Tann, M., \& Stasch, M. (2007). The operationalized psychodynamic diagnostics system: Clinical relevance, reliability and validity. Psychopathology, 40, 209220. https://doi.org/10.1159/000101363 
Clark, L. A. (2005). Temperament as a unifying basis for personality and psychopathology. Journal of Abnormal Psychology, 114, 505-521. https://doi.org/10.1037/0021-843X.114.4.505

Crawford, T. N., Cohen, P., First, M. B., Skodol, A. E., Johnson, J. G., \& Kasen, S. (2008). Comorbid axis I and axis II disorders in early adolescence: Outcomes 20 years later. Archives of General Psychiatry, 65, 641-648. https://doi.org/10.1001/archpsyc.65.6.641

Dinger, U., Schauenburg, H., Hörz, S., Rentrop, M., Komo-Lang, M., Klinkerfuß, M. ... Ehrenthal, J. C. (2014). Self-report and observer ratings of personality functioning: A study of the OPD system. Journal of Personality Assessment, 96, 220-225. https://doi.org/10.1080/00223891.2013.828065

Fertuck, E. A., Grinband, J., \& Stanley, B. (2013). Facial trust appraisal negatively biased in borderline personality disorder. Psychiatry Research, 207, 195-202. https://doi.org/10.1016/j.psychres.2013.01.004

Fincham, F. D., Beach, S. R. H., Harold, G. T., \& Osborne, L. N. (1997). Marital satisfaction and depression: Different causal relationships for men and women? Psychological Science, 8, 351-356. https://doi.org/10.1111/j.1467-9280.1997.tb00424.x

Fredrickson, B. L. (2000). Extracting meaning from past affective experiences: The importance of peaks, ends, and specific emotions. Cognition and Emotion, 14, 577-606. https://doi.org/10.1080/026999300402808

Frodl, T., Möller, H. -J., \& Meisenzahl, E. (2008). Neuroimaging genetics: New perspectives in research on major depression? Acta Psychiatrica Scandinavica, 118, 363-372. https://doi.org/10.1111/j.16000447.2008.01225.x

Goodman, M., Chowdhury, S., New, A. S., \& Siever, L. J. (2015). Depressive disorders in borderline personality disorder: Phenomenology and biological markers. In L. W. Choi-Kain \& J. G. Gunderson (Eds.), Borderline personality and mood disorders: Comorbidity and controversy (pp. 13-37). New York, NY: Springer. https://doi.org/10.1007/978-1-4939-1314-5_2

Gross, J. J. (2014). Emotion regulation: Conceptual and empirical foundations. In J. J. Gross (Ed.), Handbook of emotion regulation ( $2^{\text {nd }}$ ed., pp. 3-20). New York, NY: Guilford Press.

Gunderson, J. G. (2007). Disturbed relationships as a phenotype for borderline personality disorder. The American Journal of Psychiatry, 164, 1637-1640. https://doi.org/10.1176/appi.ajp.2007.07071125

Gunderson, J. G. \& Lyons-Ruth, K. (2008). BPD's interpersonal hypersensitivity phenotype: A geneenvironment-developmental model. Journal of Personality Disorders, 22, 22-41. https://doi.org/10.1521/pedi.2008.22.1.22

Gunderson, J. G., Morey, L. C., Stout, R. L., Skodol, A. E., Shea, M. T., McGlashan, T. H. ... Bender, D. S. (2004). Major depressive disorder and borderline personality disorder revisited: Longitudinal interactions. The Journal of Clinical Psychiatry, 65, 1049-1056. https://doi.org/10.4088/JCP.v65n0804

Gunderson, J. G. \& Phillips, K. A. (1991). A current view of the interface between borderline personality disorder and depression. The American Journal of Psychiatry, 148, 967-975. https://doi.org/10.1521/pedi_2017_31_338

Heim, C. \& Binder, E. B. (2012). Current research trends in early life stress and depression: Review of human studies on sensitive periods, gene-environment interactions, and epigenetics. Experimental Neurology, 233, 102-111. https://doi.org/10.1016/j.expneurol.2011.10.032

Herpertz, S. C. \& Bertsch, K. (2015). A new perspective on the pathophysiology of borderline personality disorder: A model of the role of oxytocin. The American Journal of Psychiatry, 172, 840-851. https://doi.org/10.1176/appi.ajp.2015.15020216

Herpertz, S. C., Huprich, S. K., Bohus, M., Chanen, A., Goodman, M., Mehlum, L. ... Sharp, C. (2017). The challenge of transforming the diagnostic system of personality disorders. Journal of Personality Disorders, 31, 577-589. https://doi.org/10.1521/pedi_2017_31_338

Herpertz, S., Steinmeyer, E. M., \& Saß, H. (1998). On the conceptualisation of subaffective personality disorders. European Psychiatry, 13, 9-17. https://doi.org/10.1016/S0924-9338(97)86746-6

Hufford, M. R., Shiffman, S., Paty, J., \& Stone, A. A. (2001). Ecological momentary assessment: Real-world, real-time measurement of patient experience. In J. Fahrenberg \& M. Myrtek (Eds.), Progress in ambulatory assessment: Computer-assisted psychological and psychophysiological methods in monitoring and field studies (pp. 69-92). Ashland, OH: Hogrefe/Huber Publishers.

Klein, D. N. (2010). Chronic depression: Diagnosis and classification. Current Directions in Psychological Science, 19, 96-100. https://doi.org/10.1177/0963721410366007

Klein, D. N., Kotov, R., \& Bufferd, S. J. (2011). Personality and depression: Explanatory models and review of the evidence. Annual Review of Clinical Psychology, 7, 269-295. https://doi.org/10.1146/annurevclinpsy-032210-104540 
Köhling, J., Ehrenthal, J. C., Levy, K. N., Schauenburg, H., \& Dinger, U. (2015). Quality and severity of depression in borderline personality disorder: A systematic review and meta-analysis. Clinical Psychology Review, 37, 13-25. https://doi.org/10.1016/j.cpr.2015.02.002

Kotov, R., Gamez, W., Schmidt, F., \& Watson, D. (2010). Linking "big" personality traits to anxiety, depressive, and substance use disorders: A meta-analysis. Psychological Bulletin, 136, 768-821. https://doi.org/10.1037/a0020327

Kramer, U. (2017). Personality, personality disorders, and the process of change. Psychotherapy Research, Advance online publication. https://doi.org/10.1080/10503307.2017.1377358 Retrieved from https://www.tandfonline.com/doi/full/10.1080/10503307.2017.1377358

Krause, M., Altimir, C., Pérez, J. C., \& de la Parra, G. (2015). Generic change indicators in therapeutic processes with different outcomes. Psychotherapy Research, 25, 533-545. https://doi.org/10.1080/10503307.2014.935516

Leichsenring, F., Leibing, E., Kruse, J., New, A. S., \& Leweke, F. (2011). Borderline personality disorder. The Lancet, 377, 74-84. https://doi.org/10.1016/S0140-6736(04)16770-6

Leising, D. \& Zimmermann, J. (2011). An integrative conceptual framework for assessing personality and personality pathology. Review of General Psychology, 15, 317-330. https://doi.org/10.1037/a0025070

Levy, K. N., Meehan, K. B., Clouthier, T. L., Yeomans, F. E., Lenzenweger, M. F., Clarkin, J. F., \& Kernberg, O. F. (2017). Transference-focused psychotherapy for adult borderline personality disorder. In D. B. Fishman, S. B. Messer, D. J. A. Edwards, \& F. M. Dattilio (Eds.), Case studies within psychotherapy trials: Integrating qualitative and quantitative methods (pp. 190-245). New York, NY: Oxford Univerity Press.

Lieb, K., Zanarini, M. C., Schmahl, C., Linehan, M. M., \& Bohus, M. (2004). Borderline personality disorder. The Lancet, 364, 453-461. https://doi.org/10.1016/S0140-6736(04)16770-6

Luyten, P., Lowyck, B., \& Blatt, S. J. (2017). Mechanisms of change through the lens of two-polarities models of personality development: State of the art and new directions. Psychoanalytic Inquiry, 37, 179-190. https://doi.org/10.1080/07351690.2017.1285187

Markowitz, J. C., Skodol, A. E., \& Bleiberg, K. (2006). Interpersonal psychotherapy for borderline personality disorder: Possible mechanisms of change. Journal of Clinical Psychology, 62, 431-444. https://doi.org/10.1002/jclp.20242

Mneimne, M., Fleeson, W., Arnold, E. M., \& Furr, R. M. (2018). Differentiating the everyday emotion dynamics of borderline personality disorder from major depressive disorder and bipolar disorder. Personality Disorders: Theory, Research, and Treatment, 9, 192-196. https://doi.org/10.1037/per0000255

Neacsiu, A. D., Eberle, J. W., Kramer, R., Wiesmann, T., \& Linehan, M. M. (2014). Dialectical behavior therapy skills for transdiagnostic emotion dysregulation: A pilot randomized controlled trial. Behaviour Research and Therapy, 59, 40-51. https://doi.org/10.1016/j.brat.2014.05.005

Newton-Howes, G., Tyrer, P., Johnson, T., Mulder, R., Kool, S., Dekker, J., \& Schoevers, R. (2014). Influence of personality on the outcome of treatment in depression: Systematic review and meta-analysis. Journal of Personality Disorders, 28, 577-593. https://doi.org/10.1521/pedi_2013_27_070

OPD Task Force (Ed.) (2008). Operationalized psychodynamic diagnosis OPD-2: Manual of diagnosis and treatment planning. Boston, MA: Hogrefe.

Pagano, M. E., Skodol, A. E., Stout, R. L., Shea, M. T., Yen, S., Grilo, C. M. ... Gunderson, J. G. (2004). Stressful life events as predictors of functioning: Findings from the collaborative longitudinal personality disorders study. Acta Psychiatrica Scandinavica, 110, 421-429. https://doi.org/10.1111/j.16000447.2004.00398.x

Paris, J. (2015). Mood disorders and personality disorders: Simplicity and complexity. In L. W. Choi-Kain \& J. G. Gunderson (Eds.), Borderline personality and mood disorders: Comorbidity and controversy (pp. 39). New York, NY: Springer. https://doi.org/10.1007/978-1-4939-1314-5_1

Paris, J. \& Zweig-Frank, H. (2001). A 27-year follow-up of patients with borderline personality disorder. Comprehensive Psychiatry, 42, 482-487. https://doi.org/10.1053/comp.2001.26271

Reichborn-Kjennerud, T., Czajkowski, N., Røysamb, E., Ørstavik, R. E., Neale, M. C., Torgersen, S., \& Kendler, K. S. (2010). Major depression and dimensional representations of DSM-IV personality disorders: A population-based twin study. Psychological Medicine, 40, 1475-1484. https://doi.org/10.1017/S0033291709991954

Rogers, J. H., Widiger, T. A., \& Krupp, A. (1995). Aspects of depression associated with borderline personality disorder. The American Journal of Psychiatry, 152, 268-270. https://doi.org/10.1176/ajp.152.2.268 
Safran, J. D., Muran, J. C., Samstag, L. W., \& Stevens, C. (2001). Repairing alliance ruptures. Psychotherapy: Theory, Research, Practice, Training, 38, 406-412. https://doi.org/10.1037/0033-3204.38.4.406

Samuel, D. B. \& Widiger, T. A. (2008). A meta-analytic review of the relationships between the five-factor model and DSM-IV-TR personality disorders: A facet level analysis. Clinical Psychology Review, 28, 1326 1342. https://doi.org/10.1016/j.cpr.2008.07.002

Schnell, K. \& Herpertz, S. C. (2018). Emotion regulation and social cognition as functional targets of mechanism-based psychotherapy in major depression with comorbid personality pathology. Journal of Personality Disorders, 32(Supplement), 12-35. https://doi.org/10.1521/pedi.2018.32.supp.12

Sharp, C., Wright, A. G. C., Fowler, J. C., Frueh, B. C., Allen, J. G., Oldham, J., \& Clark, L. A. (2015). The structure of personality pathology: Both general ('g') and specific ('s') factors? Journal of Abnormal Psychology, 124, 387-398. https://doi.org/10.1037/abn0000033

Shea, M. T., Stout, R. L., Yen, S., Pagano, M. E., Skodol, A. E., Morey, L. C. ... Zanarini, M. C. (2004). Associations in the course of personality disorders and axis I disorders over time. Journal of Abnormal Psychology, 113, 499-508. https://doi.org/10.1037/0021-843X.113.4.499

Silva, J. R., Vivanco-Carlevari, A., Barrientos, M., Martínez, C., Salazar, L. A., \& Krause, M. (2017). Biological stress reactivity as an index of the two polarities of the experience model. Psychoneuroendocrinology, 84, 83-86. https://doi.org/10.1016/j.psyneuen.2017.06.016

Staebler, K., Helbing, E., Rosenbach, C., \& Renneberg, B. (2011). Rejection sensitivity and borderline personality disorder. Clinical Psychology \& Psychotherapy, 18, 275-283. https://doi.org/10.1002/cpp.705

Stoffers, J., Völlm, B. A., Rücker, G., Timmer, A., Huband, N., \& Lieb, K. (2010). Pharmacological interventions for borderline personality disorder. The Cochrane Database of Systematic Reviews, 6, Article CD005653. https://doi.org/10.1002/14651858.CD005653.pub2

Trull, T. J., Solhan, M. B., Tragesser, S. L., Jahng, S., Wood, P. K., Piasecki, T. M., \& Watson, D. (2008). Affective instability: Measuring a core feature of borderline personality disorder with ecological momentary assessment. Journal of Abnormal Psychology, 117, 647-661. https://doi.org/10.1037/a0012532

Tyrer, P., Coombs, N., Ibrahimi, F., Mathilakath, A., Bajaj, P., Ranger, M. ... Din, R. (2007). Critical developments in the assessment of personality disorder. The British Journal of Psychiatry, 190(S49), s51s59. https://doi.org/10.1192/bjp.190.5.s51

Widiger, T. A. (2009). Neuroticism. In M. R. Leary \& R. H. Hoyle (Eds.), Handbook of individual differences in social behavior (pp. 129-146). New York, NY: Guilford Press.

Widiger, T. A. (2011). The DSM-5 dimensional model of personality disorder: Rationale and empirical support. Journal of Personality Disorders, 25, 222-234. https://doi.org/10.1521/pedi.2011.25.2.222

Wright, A. G., Thomas, K. M., Hopwood, C. J., Markon, K. E., Pincus, A. L., \& Krueger, R. F. (2012). The hierarchical structure of DSM-5 pathological personality traits. Journal of Abnormal Psychology, 121, 951-957. https://doi.org/10.1037/a0027669

Wright, A. G. C. \& Zimmermann, J. (2015). At the nexus of science and practice: Answering basic clinical questions in personality disorder assessment and diagnosis with quantitative modeling techniques. In S. K. Huprich (Ed.), Personality disorders: Toward theoretical and empirical integration in diagnosis and assessment (pp. 109-144). Washington, DC: American Psychological Association.

Zanarini, M. C., Frankenburg, F. R., Hennen, J., Reich, D. B., \& Silk, K. R. (2004). Axis I comorbidity in patients with borderline personality disorder: 6-year follow-up and prediction of time to remission. American Journal of Psychiatry, 161, 2108-2114. https://doi.org/10.1176/appi.ajp.161.11.2108

Zanarini, M. C., Frankenburg, F. R., Hennen, J., Reich, D. B., \& Silk, K. R. (2005). The McLean study of adult development (MSAD): Overview and implications of the first six years of prospective follow-up. Journal of Personality Disorders, 19, 505-523. https://doi.org/10.1521/pedi.2005.19.5.505

Zimmermann, J., Ehrenthal, J. C., Cierpka, M., Schauenburg, H., Doering, S., \& Benecke, C. (2012). Assessing the level of structural integration using operationalized psychodynamic diagnosis (OPD): Implications for DSM-5. Journal of Personality Assessment, 94, 522-532. https://doi.org/10.1080/00223891.2012.700664

Fecha de recepción: Octubre de 2018.

Fecha de aceptación: Noviembre de 2018. 